Table 2.

\begin{tabular}{lccc}
\hline Disease-modifying drug & $<70$ years old & $\geq 70$ years old & $p$ \\
\hline Methotrexate & $72(53.73 \%)$ & $9(40.91 \%)$ & 0.667 \\
Leflunomide & $22(16.42 \%)$ & $5(22.73 \%)$ & \\
Sulfasalazine & $2(1.49 \%)$ & $1(4.55 \%)$ & \\
Hydroxychloroquine & $6(4.48 \%)$ & $0(0 \%)$ & \\
At least two of the above & $7(5.22 \%)$ & $1(4.55 \%)$ & \\
\hline
\end{tabular}

Conclusion: DMARD concomitant treatment has been related to a higher second biological treatment survival. This beneficial effect was not observed in RA patients $\geq 70$ years of age whose second biological agent withdrawal cause was failure. In this age group, withdrawal related to adverse events was more frequent. References:

[1] Kalden JR, Schulze-Koops H. Immunogenicity and loss of response to TNF inhibitors: implications for rheumatoid arthritis treatment. Nature reviews Rheumatology. 2017;13(12):707-718.

Disclosure of Interests: None declared

DOI: 10.1136/annrheumdis-2020-eular.4979

\section{AB0280 SURVIVAL ANALYSIS ON SECOND BIOLOGIC THERAPY IN PATIENTS WITH RHEUMATOID ARTHRITIS OLDER THAN 65 YEARS}

A. Briones-Figueroa ${ }^{1}$, M. Tortosa-Cabañas ${ }^{1}$, B. A. Blanco Cáceres ${ }^{1}$, J. L. Morell Hita $^{1}$, J. Bachiller-Corral ${ }^{1}$, M. Vázquez Díaz ${ }^{1}{ }^{1}$ Ramón y Cajal University Hospital, Department of Rheumatology, Madrid, Spain

Background: Patients with Rheumatoid Arthritis (RA) $\geq 65$ years old constitute an important and not very well studied group. Even though the course of the disease may be similar to that of younger patients, treatment is usually less aggressive given the limited information on efficacy, especially of biological treatments, in this age group.

Objectives: To describe the characteristics of patients with RA $\geq 65$ years old who started a second biological agent. To compare the survival of this second-line treatment between patients $\geq 65$ and $<65$ years old.

Methods: Retrospective, observational and longitudinal study. Patients diagnosed of RA, who started a second biological agent between 2000 and 2019 , who discontinued a first-line TNF inhibitor, were included. Demographic, clinical and analytical data were obtained. The sample was divided in 2 groups: $<65$ and $\geq 65$ years old. Kaplan Meier and Log-rank survival analysis were performed, as well as Cox regression to identify related factors.

Results: 157 patients were identified, $42(26.8 \%)$ were $\geq 65$ years old. In this group, $73.8 \%$ were women, with a mean age at the beginning of second biological treatment of $71.43 \pm 4.76$ years. Demographic and clinical data of $\geq 65$ years old patients are shown in the table. The most frequent second biological agent was Rituximab (23.8\%), followed by Adalimumab (21.4\%) and Tocilizumab (19\%). $76.2 \%$ of patients had a disease-modifying drug associated, being Methotrexate the most frequent $(45.2 \%)$. Discontinuation of second biological agent occurred in 30 patients $(71.42 \%) \geq 65$ years old, which is similar to the percentage found in patients $<65$ years old $(66.96 \% ; p=0.70)$. The main causes of withdrawal of second-line agent in patients $\geq 65$ years were adverse effects $(23.8 \%)$ and secondary failure $(23.8 \%)$, whereas in $<65$ years were primary and secondary failure (18.3\% in both). Infections were more frequent in patients $\geq 65$ years $(14.3 \%$ ) in comparison with patients $<65$ years $(6.1 \%)$. In the survival analysis of the second biological agent, patients $\geq 65$ years presented a median survival of 45 months (IC-95\%=14.10-75.90); while patients $<65$ years had a median survival of 47 months (IC- $95 \%=29.55$ $64.46)$, without statistically significant differences $(p=0.803)$ (See Figure). Among elderly patients no statistically significant differences were found after comparison of survival curves in the subgroups: $65-69,70-74$ and $\geq 75$ years. Rituximab presented a higher survival rate in patients $\geq 65$ years $(84.3$ months; $p<0.001)$, followed by Abatacept (58.5 months). Smoking (HR=13.96; IC- $95 \%=2.12-91.93)$, erosions $(H R=7.04 ; I C-95 \%=1.05-47.31)$ and diabetes mellitus (HR=13.37; IC-95\%=1.25-143.46) were identified as risk factors for discontinuation of second biologic agent.

Conclusion: The survival of second biological agent after the failure of a first TNF inhibitor in patients $\geq 65$ years is similar to the survival in younger patients, although there was a higher percentage of adverse effects in the first group. Rituximab and Abatacept showed a higher survival in patients $\geq 65$ years. Smoking, erosions and diabetes mellitus were associated with an increased risk for the withdrawal of the second-line biological therapy.

References:

[1] Richter M, Matteson E, DavisIII J, Achenbach S, Crowson C. Comparison of Biologic Discontinuation in Patients With Elderly-Onset Versus Younger-Onset Rheumatoid Arthritis. ACR Open Rheumatology. 2019; 1(10): 627-631.

\section{Variables} $\mathrm{n}=42($ mean $\pm \mathrm{SD}$ or $\%)$

Age at diagnosis (years)

Age at the beginning of the treatment (years)

Women

Smokers

$\mathrm{RF}(+)$

ACPA (+)

Erosion

Arterial hypertension

Diabetes mellitus

Dyslipidemia

Disease-modifying drug

Methotrexate

Leflunomide

Sulfasalazine

Hydroxychloroquine

Infections

Respiratory infection

Skin/Soft tissues infection

Herpes zoster

$56.48 \pm 9.94$

$71.43 \pm 4.76$

$31(73.8 \%)$

$11(26.2 \%)$

$35(83.3 \%)$

$30(71.4 \%)$

$21(50 \%)$

$4(9.5 \%)$

$11(26.2 \%)$

$19(45.2 \%)$

$10(23.8 \%)$

$1(2.4 \%)$

$0(0 \%)$

$3(7.1 \%)$

$2(4.8 \%)$

$1(2.4 \%)$

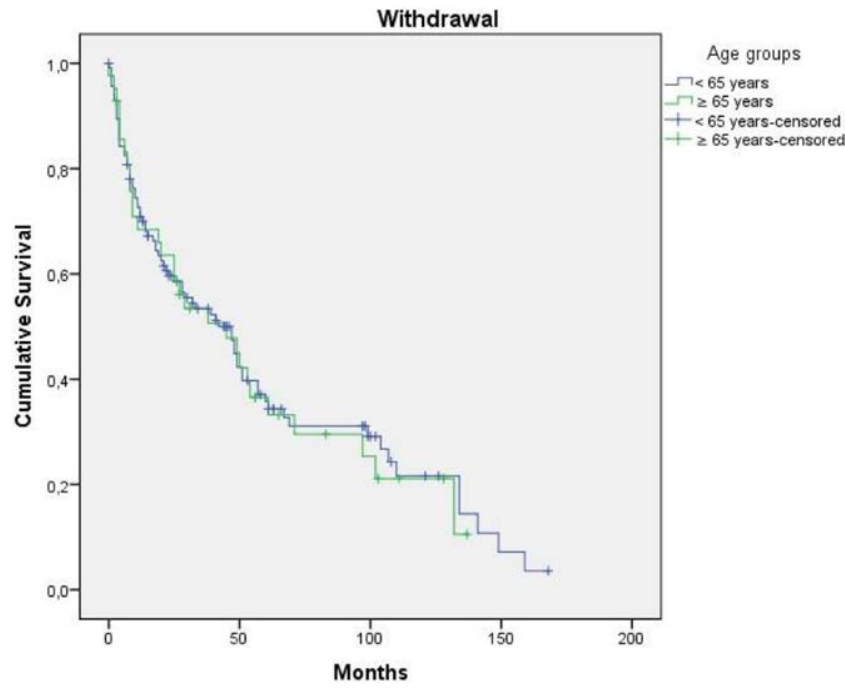

Disclosure of Interests: None declared

DOI: 10.1136/annrheumdis-2020-eular.4911

\section{AB0281 \\ SAFETY AND RETENTION RATE AFTER SWITCHING FROM ETANERCEPT ORIGINATOR (ETN) TO ETANERCEPT BIOSIMILAR (SB4) IN INFLAMMATORY JOINT DISEASES: DATA FROM REAL LIFE.}

C. Bruni ${ }^{1}$, S. Gentileschi ${ }^{2}$, M. Capassoni ${ }^{1}$, G. Pacini ${ }^{1}$, M. Bardelli ${ }^{2}$, C. Baldi ${ }^{2}$ L. Tofani ${ }^{1}$, L. Cometi ${ }^{1}$, F. Nacci' ${ }^{1}$,F. Bartoli ${ }^{3}$, G. Fiori ${ }^{3}$, L. Cantarini ${ }^{2}$,

S. Guiducci ${ }^{1,3}$, B. Frediani ${ }^{2}$, M. Matucci-Cerinic ${ }^{1,3} .{ }^{1}$ University of Florence, Faculty of Medicine, Experimental and Clinical Medicine, Division of Rheumatology, Firenze, Italy; ${ }^{2}$ University of Siena, Medical Sciences, Surgery and Neurosciences, Rheumatology Unit, Siena, Italy; ${ }^{3}$ Careggi University Hospital, Rheumatology, Firenze, Italy

Background: SB4 in now commonly used in the treatment of inflammatory joint diseases, with evidence of efficacy and persistence up to 12 months from switching in both randomized controlled trials in Rheumatoid Arthritis (RA), Psoriatic Arthritis (PsA) and Ankylosing Spondylitis (AS).

Objectives: we investigated the safety and retention rate of SB4 at 6,12 and 18 months after switching from ETN in two rheumatology departments in our region. Methods: adult patients with RA, PsA, AS, Juvenile Idiopathic Arthritis (JIA) and other rheumatic diseases treated with ETN for at least 6 months, switched to SB4 in stable clinical conditions, were eligible for this retrospective evaluation. Data on adverse events (in particular infectious events), loss of efficacy (articular, cutaneous, ocular or intestinal disease re-activation) and persistence on treatment were collected since latest available follow-up. Retention rate, reason for discontinuation and subsequent management data were collected at $6,12,18$ months. Results: 220 patients (142 females, mean age 58+-7 years, disease duration 12+-4 years, ETN duration 7+-4 years) were enrolled, with median follow up of 12.1 (9.7-15.8) months duration; ETN was used in different biologic DMARDs treatment lines (first $76.8 \%$, second $17.7 \%$, third $3.2 \%$, fourth $2.3 \%$ ). Study 
population was composed of 85 RA, 81 PsA, 33 AS, 14 JIA and 7 other conditions (mostly scleroderma). In the follow-up, 50 patients $(22.7 \%)$ presented with at least one non-serious adverse event, with $36(16,4 \%)$ disease re-activation (mostly articular) and 30 (13,6\% - 11 for safety and 19 loss of efficacy) SB4 interruptions. Retention rates were $99.1(210 / 212)$ at $6,90.9 \%(150 / 165)$ at 12 and $81.5 \%(53 / 65)$ at 18 months respectively. Back-switch to ETN was performed in $17 / 30$ cases, the remaining cases were managed with change of bDMARD or csDMARD). Age was the only significant predictor of SB4 interruption at 6 months (OR 1.058, 95\% $1.007-1.112, p=0.026$ ), while disease, bDMARD line, csDMARD combination, gender, disease duration or ETN duration did not influence retention rates at 6,12 or 18 months.

Conclusion: our real-life data confirm the safety profile of switching from ETN to SB4. In our patients, the data show a higher retention rate, when compared to other-real life registries data $(1,2)$

References:

[1] Ebbers HC et al. Real-World evidence on Etanercept Biosimilar SB4 in Etanercept-Naïve or Switching Patients: A Systematic Review. Rheumatol Ther. 2019 Sep;6(3):317-338.

Disclosure of Interests: Cosimo Bruni Speakers bureau: Actelion, Eli Lilly, Stefano Gentileschi: None declared, Marco Capassoni: None declared, Giovanni Pacini: None declared, Marco Bardelli: None declared, Caterina Baldi: None declared, Lorenzo Tofani: None declared, Laura Cometi: None declared, Francesca Nacci: None declared, Francesca Bartoli: None declared, Ginevra Fiori: None declared, Luca Cantarini: None declared, Serena Guiducci: None declared, Bruno Frediani: None declared, Marco Matucci-Cerinic Grant/research support from: Actelion, MSD, Bristol-Myers Squibb, Speakers bureau: Acetelion, Lilly, Boehringer Ingelheim

DOI: 10.1136/annrheumdis-2020-eular.1948

\begin{tabular}{|l|l}
\hline AB0282 & CLINICAL EFFECTIVENESS OF ABATACEPT \\
MONOTHERAPY OR ABATACEPT CONCOMITANT \\
METHOTREXATE THERAPY IN RHEUMATOID \\
ARTHRITIS PATIENTS PREVIOUSLY TREATED WITH \\
BIOLOGICAL DISEASE-MODIFYING ANTIRHEUMATIC \\
DRUGS (BDMARDS)
\end{tabular}

N. Márquez Pete ${ }^{1,2}$, M. D. M. Maldonado Montoro ${ }^{3}$, C. Pérez Ramírez ${ }^{4}$, R. Cáliz Cáliz $^{5}$, A. Jiménez Morales ${ }^{6} .{ }^{1}$ Virgen de las Nieves University Hospital, Pharmacy Service. Pharmacogenetics Unit, Granada, Spain; ${ }^{2}$ Universidad de Granada, Granada, Spain; ${ }^{3}$ Clínico San Cecilio University Hospital, Clinical Analysis Service, Granada, Spain; ${ }^{4}$ Virgen de la Macarena University Hospital, Pharmacy Service, Pharmacogenetics Unit, Sevilla, Spain; ${ }^{5}$ Virgen de las Nieves University Hospital, Rheumatology Service, Granada, Spain; ${ }^{6}$ Virgen de las Nieves University Hospital, Pharmacy Service, Granada, Spain

Background: Concomitant use of methotrexate (MTX) in abatacept (ABA) therapy is associated with good clinical response in patients with rheumatoid arthritis (RA) who are naïve to biological disease-modifying antirheumatic drugs (bDMARDs) $)^{1,2}$. However, it is unclear when abatacept is used in patients with prior bDMARDs use ${ }^{3}$.

Objectives: We compared the effectiveness of abatacept monotherapy versus abatacept combined with methotrexate therapy in rheumatoid arthritis patients with prior bDMARDs use.

Methods: Retrospective cohorts study. Rheumatoid arthritis patients treated with abatacept between 2009 and $2019(n=86)$. Socio-demographic, clinical and pharmacological characteristics of patients were collected. We compared clinical effectiveness between ABA monotherapy patients $(n=49)$ and abatacept concomitant methotrexate therapy patients $(n=37)$, prior treated with bDMARDs. The effectiveness was measured according to The European League Against Rheumatism (EULAR) response with Disease Activity Score (DAS28) like satisfactory (DAS28<3.2) or unsatisfactory (DAS28 $\geq 3.2$ ), after 12 months of ABA therapy in RA patients.

Results: 49 RA patients have been evaluated in ABA monotherapy group; $83.67 \%(41 / 49)$ were women, disease duration was $16(10-22)$ years and age of RA diagnosis was 48 (38.25-57.00). Concomitants glucocorticoids were administrated in $81.63 \%$ (40/49). Rheumatoid factor (RF) was positive in $75.51 \%$ (37/49) patients and cyclic citrullinated peptide antibodies (ACPA) in $71.43 \%$ (35/49). At 12 months, 40.82\% (20/49) of patients had satisfactory EULAR response.

In the combination therapy group, the age of RA diagnosis was 42.5 (35.75$53.50), 75.68 \%(28 / 37)$ were women and the disease duration was $12(7-21)$ years. $89.19 \%(33 / 37)$ had concomitants glucocorticoids and the RF was positive in $72.97 \%(27 / 37)$ of patients. EULAR response was satisfactory at 12 month in $43.24 \%(16 / 37)$ of patients. No difference in treatment effectiveness was found in patients receiving abatacept in combination therapy with MTX compared with ABA monotherapy $\left(p=0.829 ; I_{95}=0.35-2.35\right)$.
Conclusion: Abatacept plus methotrexate therapy did not improve the effectiveness in rheumatoid arthritis patients with prior bDMARDs use, compared with abatacept monotherapy.

\section{References:}

[1] Genovese M, Schiff M, Luggen M, Becker J, Aranda R, Teng J, et al. Efficacy and safety of the selective co-stimulation modulator abatacept following 2 years of treatment in patients with rheumatoid arthritis and an inadequate response to anti-tumour necrosis factor therapy. Annals of the rheumatic diseases. 2008;67(4):547-54.

[2] Smolen JS, Landewe RBM, Bijlsma JWJ, Burmester GR, Dougados M, Kerschbaumer A, et al. EULAR recommendations for the management of rheumatoid arthritis with synthetic and biological disease-modifying antirheumatic drugs: 2019 update. Ann Rheum Dis. 2020.

[3] Walker UA, Jaeger VK, Chatzidionysiou K, Hetland ML, Hauge E-M, Pavelka K, et al. Rituximab done: what's next in rheumatoid arthritis? A European observational longitudinal study assessing the effectiveness of biologics after rituximab treatment in rheumatoid arthritis. Rheumatology. 2016;55(2):230-6

Disclosure of Interests: None declared

DOI: 10.1136/annrheumdis-2020-eular.6047

RBD283
REDUCED HOSPITAL ADMISSION IN RA PATIENTS
TAPERING BIOLOGIC DMARDS: PRELIMINARY
ANALYSIS OF A RETROSPECTIVE STUDY

D. Camellino ${ }^{1}$, A. Giusti ${ }^{1}$, G. Girasole ${ }^{1}$, C. Craviotto ${ }^{1}$, P. Diana ${ }^{1}$, A. Locaputo ${ }^{1}$, T. Caviglia ${ }^{1}$, L. Luca ${ }^{1}$, G. Bianchi ${ }^{1} .{ }^{1}$ Azienda Sanitaria Locale ${ }^{3}$, Division of Rheumatology, La Colletta Hospital, Arenzano, Italy

Background: bDMARDs are among the most effective therapies in the management of inflammatory arthritides, but they are associated with potentially severe adverse events (AEs), particularly infection. Tapering strategies of bDMARDs for patients in remission/low disease activity (R/LDA) have demonstrated comparable efficacy to standard-dose treatments, but their safety profile has not been studied yet.

Objectives: To compare the number and the causes of hospital admissions in RA patients in R/LDA continuing or tapering bDMARDs.

Methods: Consecutive patients with rheumatoid arthritis (RA) evaluated between 2011 and 2017, were assigned, based on treating physician's discretion, to continue the standard dose (STD) of bDMARDs or to undergo a predetermined tapering strategy (TAP), after being in R/LDA for two consecutive visits at least 3 months apart. Down-titration of bDMARDs was obtained by a stepwise increase of the dosing interval to achieve a reduction of about $30 \%$ (e.g. administration of etanercept every 10 days instead of weekly). Demographic, clinical data and concomitant treatments were retrospectively retrieved from the electronic charts of the outpatient clinics. Information about hospital admissions, including main diagnosis, period and duration of hospitalization, and death were retrieved from the Regional Healthcare System Database.

For the STD group, the observation period started with the occurrence of remission and finished with one of these events: loss of remission, switch to another bDMARD, withdrawal of the bDMARD, severe AE, death, end of the study period in (December 2017). For the TAP group, the observation period started with tapering onset and finished with one of these events: reduction of the dosing interval due to either a relapse (according to a DAS28 increase) or to a subjective, symptomatic relapse (according to the patient's definition), switch to another bDMARD withdrawal of the bDMARD, severe AE, death, end of the study period in (December 2017).

Results: 81 patients were included, of whom 40 underwent TAP. Demographic clinical and treatment data are shown in table 1. Baseline characteristics were comparable between the two groups, except for the number of previous bDMARDs before observational period entry that was slightly higher in the STD group (STD $1.0 \pm 0.9$ versus TAP $0.5 \pm 0.8, P=0.11$ ).

Table 1. Baseline demographic and clinical characteristics of the patients in remission or low disease activity.

\begin{tabular}{lccc}
\hline & $\begin{array}{c}\text { NO TAPERING } \\
(\mathbf{n}=\mathbf{4 1})\end{array}$ & $\begin{array}{c}\text { TAPERING } \\
(\mathbf{n}=\mathbf{4 0})\end{array}$ & p value \\
\hline Mean age (yrs) & $57 \pm 11$ & $58 \pm 13$ & 0.563 \\
Mean disease duration (yrs) & $12 \pm 9$ & $12 \pm 7$ & 0.897 \\
Starting bDMARD to tapering/monitoring (months) & $52 \pm 45$ & $67 \pm 41$ & 0.128 \\
Mean monitoring period (months) & $22 \pm 24$ & $19 \pm 23$ & 0.632 \\
Taking sDMARD at any time ((n) (\%)) & $40(98 \%)$ & $37(92 \%)$ & 0.359 \\
Taking glucocorticoids & $29(71 \%)$ & $28(70 \%)$ & 0.999 \\
Mean prednisone dose (mg/day) & $2.5 \pm 2.9$ & $2.1 \pm 2.7$ & 0.527 \\
DAS28 at the time of tapering or first LDA/REM & $2.3 \pm 0.8$ & $2.3 \pm 0.9$ & 0.863 \\
Previous bDMARDs $>1$ ( $(\mathrm{m}(\%))$ & $10(24.4 \%)$ & $4(10 \%)$ & 0.140 \\
\hline
\end{tabular}

